\title{
Open-source implementation of an integrated, low-cost environmental mon- itoring system (EMS) for developing countries
}

\author{
B.H. Sudantha ${ }^{a}$, K.M.H.K. Warnakulasooriya ${ }^{a}$, Y.P. Jayasuriya ${ }^{a}$, \\ G.R. Ratnayaka ${ }^{b 1}$, P.K.S. Mahanama ${ }^{b}$, E.J. Warusavitharana ${ }^{b}$ and S.N. Weerasinghe $^{b}$ \\ ${ }^{a}$ Faculty of Information Technology, University of Moratuwa, Sri Lanka \\ ${ }^{\mathrm{b}}$ Department of Town \& Country Planning, University of Moratuwa, Sri Lanka
}

\begin{abstract}
Whilst widely accepted as an important facet of Open Source technologies and their application, the scientific evaluation of such technologies and systems is often underexplored in research. This work presents an integrated approach of developing a prototype Environmental Monitoring System (EMS) based on open source hardware \& software, and the system's reliability in terms of data accuracy. The system is able to measure nine environmental parameters: rainfall, temperature, barometric pressure, humidity, wind speed, wind direction, solar radiation, soil moisture and water level. Opposing to sophisticated and conventional environmental data collection systems such as automatic and manual weather stations belong to Meteorological and Irrigation department of Sri Lanka, this research has shown a promising way of establishing a dense coverage to monitor the environmental phenomena in a more cost effective manner.
\end{abstract}

Keywords: Automatic weather stations, Non conventional, Open-source environmental monitoring information, Real time data, Sensors

\section{Introduction}

This research is based on an emerging domain called Internet of Things (IoT), which has a great potential for societal, environmental as well as economic impact (Coetzee \& Eksteen, 2011) that ultimately enables smarter decisions. The term Internet of Things (IoT) is simply the point in time when more "things or objects" were connected to the internet than people (Evans, 2011). IoT has been around for the past few years and is gaining recognition with the breakthrough of advanced wireless technology (Huang \& Li, 2010; Ucklemann, Harrison, \& Michahelles, 2011). The most important thing in IoT is it provides the necessary infrastructure to transparently access sensors, processes and actuators using standardized protocols regardless of hardware, operating systems or location (Presser, et al., 2009; Roggen, et al., 2013).

The IoT based applications have been started to become popular as a more cost effective product, after the integration of open hardware and open software in system development. The open source software packages and open hardware sensors have become widely used on a global scale in reducing costs of environmental monitoring (Bitella, et.al, 2014; Formisano, Massera, \& De Vito, 2015; Sadler, et.al, 2014; Samourkasidis \& Athanasiadis, 2014; Prescott, et.al, 2016). In Sri Lankan context, IoT intergraded innovative experiments have been used in environmental assessment research areas such as safety and fear of crime (De Silva, Warusavitharana \& Ratnayake, 2017; Ratnayake, 2013; Ratnayake, 2016; Ratnayake, 2017; Ranasinghe et al., 2016).

According to Artiola, Pepper, and Brusseau (2004) and Wiersma (2004) "Environmental Monitoring" is defined as the systematic sampling of air, water, soil, and biota in order to observe and study the environment, as well as to derive knowledge of this process. In this study, the term "System" refers to a set-up which worked as a station networked by a wireless protocol. For the purpose of this study, the term "Environmental Monitoring System" (EMS) refers to a station networked by a wireless protocol which systematically observe and collect data on environment, especially with regard to air, water and soil. Hence, within the concept of IoT, with reference to environmental data, a new opportunity is given by the usage of non-conventional sources to collect information of several parameters.

In this view, non-conventional systems and sensors (low cost devices automatically providing measures) will be more and more important in the future, either as a complement to standard and authoritative monitoring systems or as a vital data source in regions where 
traditional observation networks are in decline or missing (Bell, Cornford, and Bastin, 2013). In fact, these "crowdsourced" data (Muller et al., 2015) are very attractive due to their nature of being generally available in near-real time with high spatio-temporal resolution and therefore potentially being able to fill the gap in detecting the local activities in various geographic locations that go unnoticed (Goodchild, 2007).

\section{The Approach}

Water A fast growth in mobile connectivity and smart device diffusion in developing countries have been observed (GSMA, 2014; Mierzwa et al., 2014) and this could be a great opportunity for setting-up monitoring systems at low-cost which could be used to address a number of practical issues associated with weather prediction, hazards and climatic changes.

In this background, a joint research project called "4ONSE" was commenced between University of Moratuwa, Sri Lanka and University of Applied Sciences of Arts Southern Switzerland (SUPSI). 4ONSE is the acronym for "4 times Open \& Non-conventional technologies for Sensing the Environment". This study was commenced in an era where the necessity of a low cost, non-conventional and precise environmental monitoring system is greatly demanding due to the rise in the number of natural disasters and uncertain weather predictions. As a solution for traditional and high cost weather data collection and processing procedures, this research argues a need for an open technologies based approach to monitor the environmental phenomena in a more cost effective manner.

This research assumes, some hypotheses. First, commonly accepted assumption is that the IoT has a great potential for societal, environmental as well as economic impact (Coetzee et al., 2011; Evans, 2011) enabling smarter decisions. Second is that the lack of efficient, dense and modern monitoring systems in developing countries is due to the lack of sustainable solutions that meet local needs. This is supported by evidence found in literature, that highlight how existing networks have been mainly set up by foreign countries to monitor global, rather than local, phenomena and that identified as a key factor in system failures the inaccessibility to funds and local support (Snow, 2013). Third hypothesis is given by the assumption that in the coming years the technological diffusion of mobile internet would reach most of the world, including not only the most populated areas but also the most remote regions.

Evolution of this technology in developing countries cannot exactly be predicted, but there are marketing and economic studies that forecast a fast growing diffusion of wireless connectivity and smart devices in the near future (GSMA, 2014).
Given the importance and potential of IoT, and the above formulated hypotheses, a possible solution to globally existing issues and data gaps in developing countries may be given by a fully Open and Nonconventional System for sensing the Environment. A 'Fully Open' system is composed of Open Hardware, Open Software, Open Standards, and Open Data whilst 'Non-conventional' intends a low-cost system which does not respect all the high standard requirements in terms of sensor construction, precision, and testing.

The main objective of this research is to setting-up an experimental, fully open and non-conventional environmental monitoring system which can withstand weather conditions of the country. However, the sustainability of the system as a low cost, nonconventional and universally accepted product is depend primarily on its system performance. Testing the performance of the system is a long term task, which involves collecting and analyzing data and information on sensor outputs and system errors during the stages of system development and deployment. In this research paper, only the sensor outputs have been validated to show the system's performance in terms of data accuracy.

\subsection{System Architecture}

The EMS system comprises of two stations - main station and river gauge. The main station is capable of measuring wind speed, wind direction, temperature, rainfall, humidity, solar radiation, barometric pressure, and soil moisture. The river gauge measures the water level. The EMS system has been developed as an Arduino Mega2560 based embedded system. All sensors except river gauge are directly connected to the main system. Station with river gauge has been separately developed using Arduino UNO, and necessary electronic modules.

Communication between the main system and river gauge has been established using wireless technologies. All types of processing and controlling are carried out by Arduino Mega2560 and all data collected at the station is sent to the main server using GSM technology. Figure 1 illustrates the block diagram of the main system's architecture.

The main controller of the system is Arduino Mega2560 and its functions are obtaining data from all sensors, processing some of the data before sending them to the server, controlling and communicating with other peripherals, including SD module, real time clock module (RTC), fan controller and GSM module. Figure 2 illustrates the schematic diagram of the main system. 


\subsection{The Printed Circuit Board (PCB) of the System}

The main PCB (Printed Circuit Board) was designed, including all circuit modifications of the main system. Arduino Mega controller, GSM (Global System for Mobile communication) module, RTC (Real Time Clock), fan controller, and SD modules were separately mounted within the main system box. All connections between the PCB and above mentioned modules were made by using jumper wires. This design stage comprised of three boxes as shown in Figure 3, namely main controller box (main processing unit), sensors connectivity box (sensor unit) and power control box

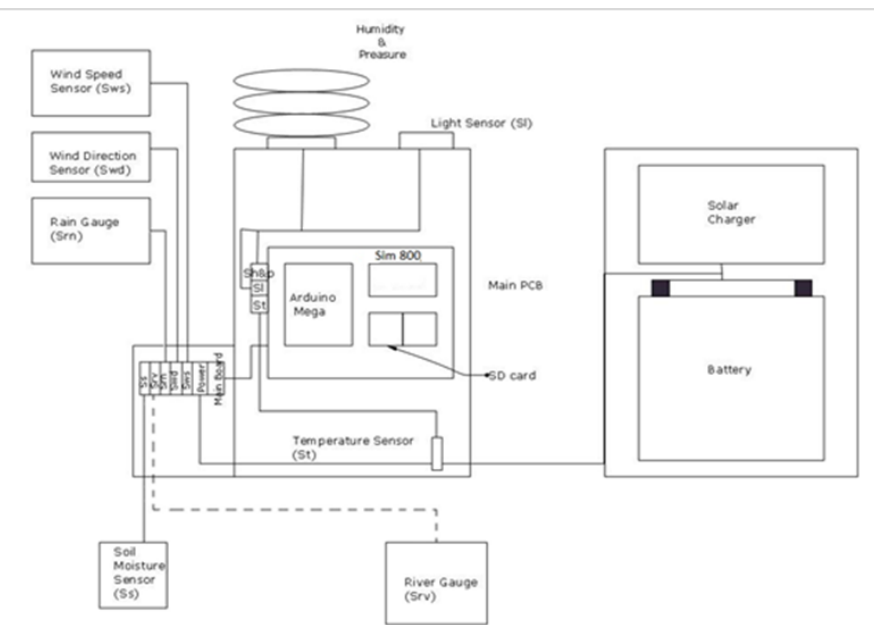

Figure 1: Block diagram of the main system architecture

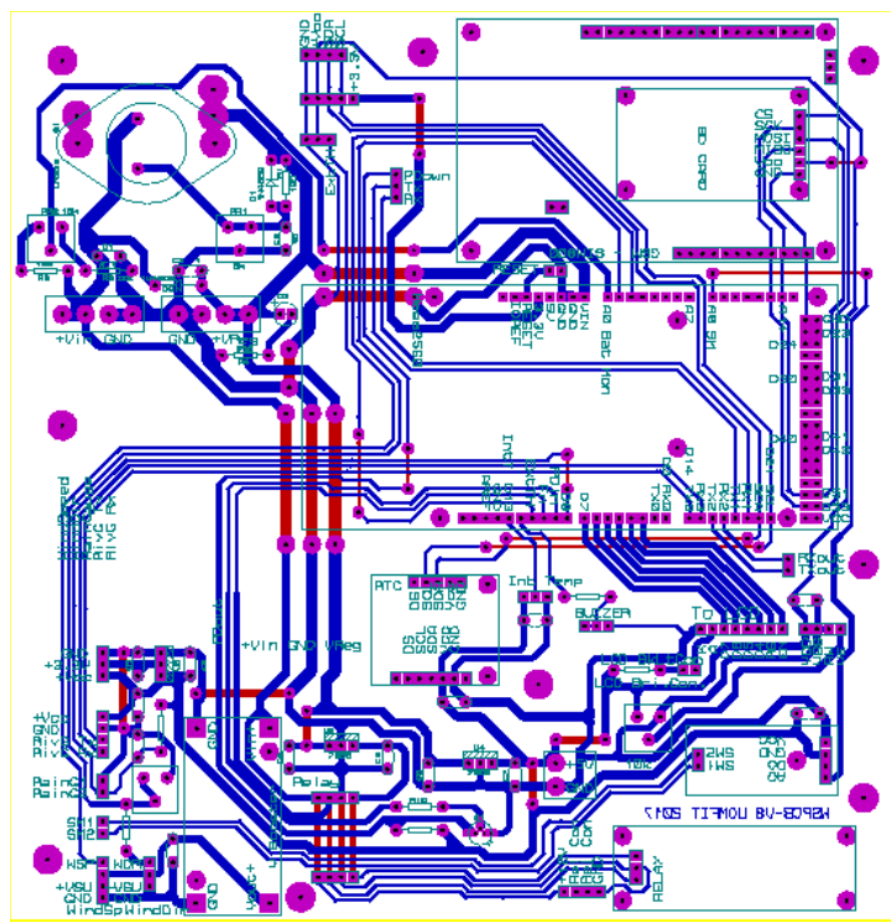

Figure 3: Block view of the initial stage of the system

\subsection{Cost Effectiveness of the EMS System}

The Taking into account the cost of each component of the system, including the main system block, power supply unit, sensor unit of the main weather station, mounting and housing items, and river gauge, total cost incurred in developing a prototype EMS system has (power supply unit). The main controller box contained the final version of the PCB with wired connection of Arduino Mega, GSM, RTC, SD module, soil

moisture signal conditioning module and fan controller. All sensors, as shown in Table 1, are connected to the sensor connectivity box and connection bus with power lines are linked between the main box and sensor connectivity box. Figure 4 illustrates the all-inclusive view of the final version of the PCB which is used in the current system, and Figure 5 illustrates the final version of the system with all components connected.

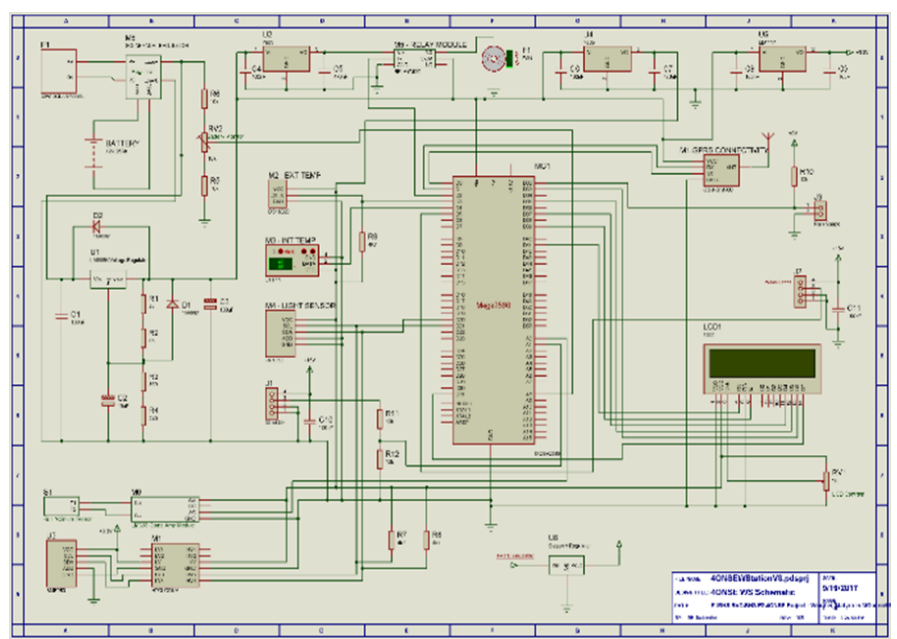

Figure 2: Schematic diagram of the main system

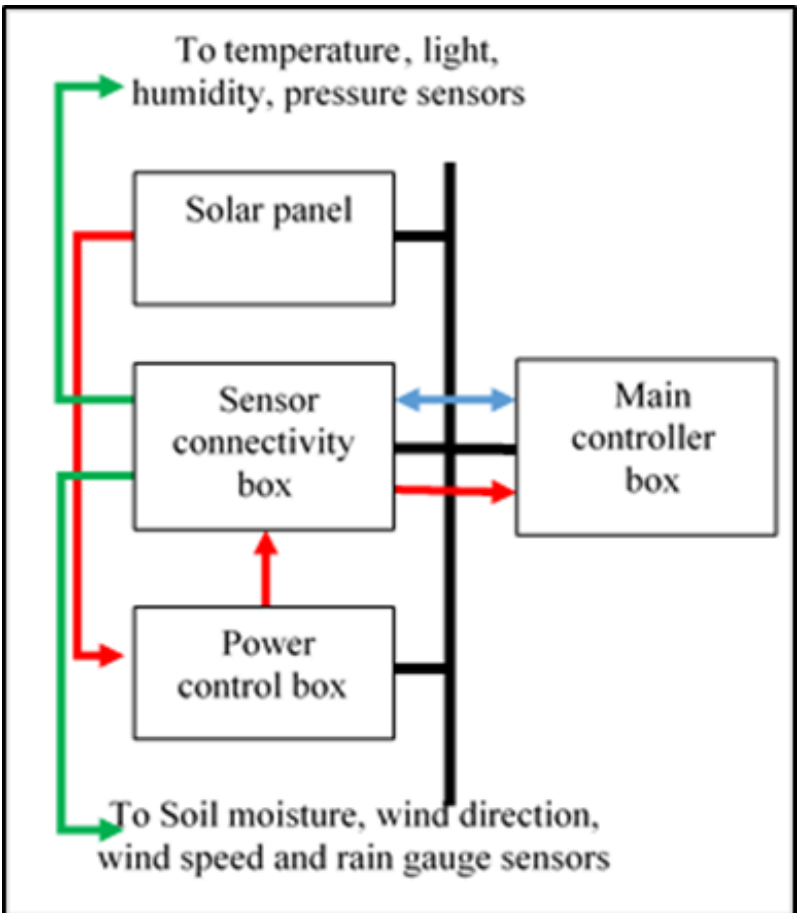

Figure 4: All-inclusive layers view of the final version of PCB (top view)

been calculated as USD 725.13. This includes a delivery charge (shipping) of USD 125.40 which is approximately $21 \%$ of total cost of developing the main station (USD 573.50) for items purchased from international market. 
In order to evaluate the cost effectiveness of the EMS system, it has been compared against other wireless and automatic weather stations that are available in the current market, and which measures similar parameters as the prototype EMS system. Table 2 shows the cost comparison along with levels of accuracies of the EMS system and other randomly selected wireless and automatic weather stations.

Although, the levels of accuracies of certain parameters vary among the prototype EMS and other stations, the system is capable of measuring nine parameters with a relatively low cost, which makes it more suitable for monitoring air, water and soil environmental parameters in developing countries.

Table 1: Sensors used in the EMS system

\begin{tabular}{|l|l|}
\hline \multicolumn{1}{|c|}{ Name of Sensor } & \multicolumn{1}{c|}{ Measured Parameter } \\
\hline DS18B20 sensor & Temperature \\
\hline BH1750 light sensor module & Light intensity \\
\hline $\begin{array}{l}\text { 4ONSE soil moisture } \\
\text { module }\end{array}$ & Soil moisture \\
\hline BME280 sensor & Atmospheric pressure \\
\cline { 2 - 3 } ZHIPU wind speed sensor & Wumidity \\
\hline $\begin{array}{l}\text { Anemometer 485 Wind } \\
\text { direction sensor }\end{array}$ & Wind direction \\
\hline $\begin{array}{l}\text { Davis AeroCone Rain } \\
\text { Collector (Product number } \\
\text { 6465) }\end{array}$ & Rainfall \\
\hline 4ONSE river gauge module & Water level \\
\hline
\end{tabular}

\section{Data Validation}

The main drawback faced by the authors on validating the data of the EMS system was unavailability of nearby reference station to get the data on nine environmental parameters. Therefore, different procedures have been followed to validate the sensor outputs of the EMS system.

Accordingly, the parameters on relative humidity, temperature and wind speed were validated against the data recorded by a reference station in the university premises. Due to a minor difference in time intervals of EMS station and reference station, the reference station tends to capture a higher number of records per minute, compared against the EMS station. The data validation for above three parameters has been shown graphically in figure 6,7 and 8 .

It is clear from Figures 6-8, that the trend line of relative humidity, temperature and wind speed measurements of both EMS and reference station follows the same pattern and direction from which we could state that EMS is capable of producing accurate measurements of above parameters to a greater extent.
Table 2: Comparison of costs and accuracy levels of parameters of the prototype EMS system and three other weather stations in the market

\begin{tabular}{|c|c|c|c|c|}
\hline \multirow[t]{2}{*}{$\begin{array}{c}\text { Measured } \\
\text { Parameters \& } \\
\text { other available } \\
\text { features }\end{array}$} & $\begin{array}{c}\text { Prototyp } \\
\text { e EMS } \\
\text { system }\end{array}$ & $\begin{array}{c}\text { Vantage } \\
\text { Pro Plus } \\
\text { Station }\end{array}$ & \begin{tabular}{|} 
MetPak \\
RG \\
Weather \\
Station
\end{tabular} & $\begin{array}{c}\text { Rainwise } \\
\text { PORTL } \\
\text { OG 805- } \\
1018 \\
\text { Portable } \\
\text { WS }\end{array}$ \\
\hline & Accuracy & Accuracy & Accuracy & Accuracy \\
\hline Rainfall & $0.2 \mathrm{~mm}$ & $0.2 \mathrm{~mm}$ & $0.2 \mathrm{~mm}$ & $0.5 \mathrm{~mm}$ \\
\hline Wind speed & $\begin{array}{c}0.2-0.4 \mathrm{~m} / \\
\mathrm{s}\end{array}$ & $12 \mathrm{~m} / \mathrm{s}$ & $12 \mathrm{~m} / \mathrm{s}$ & $+0.01 \mathrm{~m} / \mathrm{s}$ \\
\hline Wind direction & $\pm 3^{\circ}$ & $\pm 3^{\circ}$ & $\pm 3^{\circ}$ & \pm 30 \\
\hline Temperature & $\pm 0.50 \mathrm{C}$ & $\pm 0.1^{\circ} \mathrm{C}$ & $\pm 0.1^{\circ} \mathrm{C}$ & $\pm 10 \mathrm{C}$ \\
\hline Relative humidity & $\pm 3 \%$ & $\pm 0.8 \%$ & $\pm 0.8 \%$ & $2 \%$ \\
\hline $\begin{array}{c}\text { Barometric } \\
\text { Pressure }\end{array}$ & $\pm 1 \mathrm{hPa}$ & $\pm 0.5 \mathrm{hPa}$ & $\pm 0.5 \mathrm{hPa}$ & $\pm 0.5 \mathrm{hPa}$ \\
\hline $\begin{array}{l}\text { Light intensity/ } \\
\text { Solar radiation }\end{array}$ & $\begin{array}{c}1.44 \\
\text { times, } \\
\text { Sensor } \\
\text { Out / } \\
\text { Actual lx } \\
\end{array}$ & $\begin{array}{c}\text { Not } \\
\text { Available }\end{array}$ & $\begin{array}{c}\text { Not } \\
\text { Available }\end{array}$ & $\pm 5 \%$ \\
\hline Soil moisture & $\pm 2 \%$ & $\begin{array}{c}\text { Not } \\
\text { Available } \\
\end{array}$ & \begin{tabular}{|c|} 
Not \\
Available \\
\end{tabular} & $\begin{array}{c}\text { Not } \\
\text { Available } \\
\end{array}$ \\
\hline River Gauge & $\pm 0.5 \mathrm{~cm}$ & $\begin{array}{c}\text { Not } \\
\text { Available }\end{array}$ & $\begin{array}{c}\text { Not } \\
\text { Available }\end{array}$ & $\begin{array}{c}\text { Not } \\
\text { Available }\end{array}$ \\
\hline $\begin{array}{c}\text { Wireless } \\
\text { communication }\end{array}$ & $\sqrt{ }$ & $\sqrt{ }$ & $\sqrt{ }$ & $\sqrt{ }$ \\
\hline Cost & $\begin{array}{c}\text { USD } \\
725.13\end{array}$ & $\begin{array}{c}\text { USD } \\
1,295.00\end{array}$ & $\begin{array}{c}\text { USD } \\
2611.20 \\
\end{array}$ & $\begin{array}{c}\text { USD } \\
3,595.00 \\
\end{array}$ \\
\hline
\end{tabular}

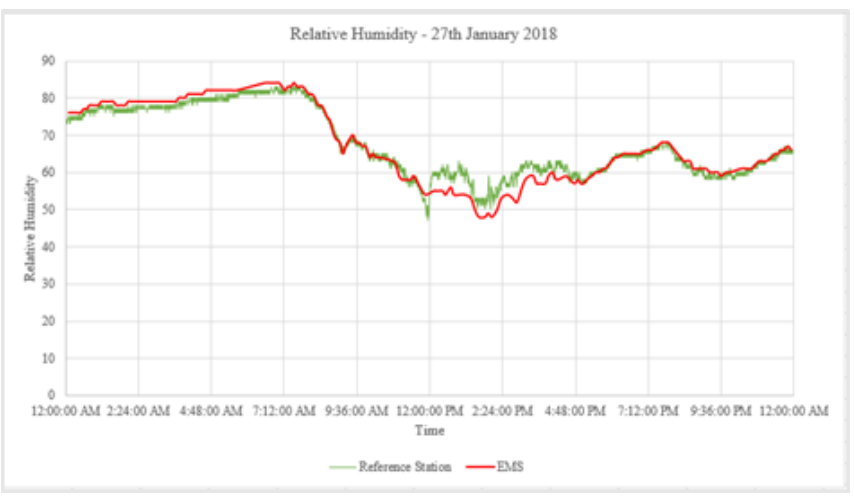

Figure 6: Relative humidity records as at 27th January 2018

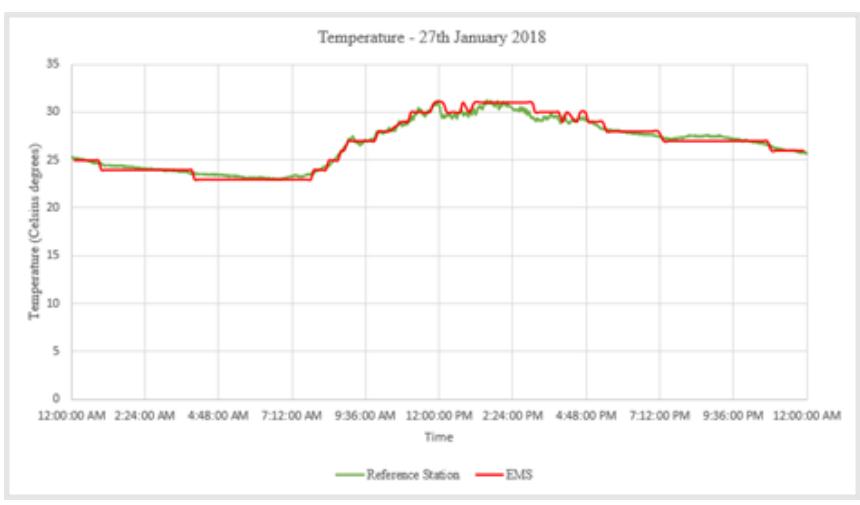

Figure 7: Temperature records as at 27th January 2018 


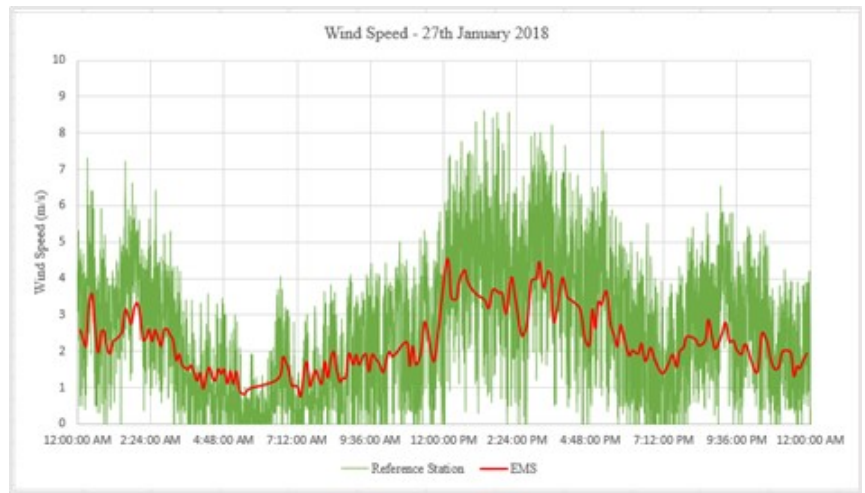

Figure 8: Wind speed records as at 27th January 2018

During the designing stage of the weather station, a bot commercially available low cost soil moisture sensor was used. Since it was caused for corrosion with the time while giving erroneous readings, the authors have developed a new soil moisture module using stainless steel tubes. Figure 9 shows the calibration curve related as to newly developed soil moisture module tested at the laboratory.

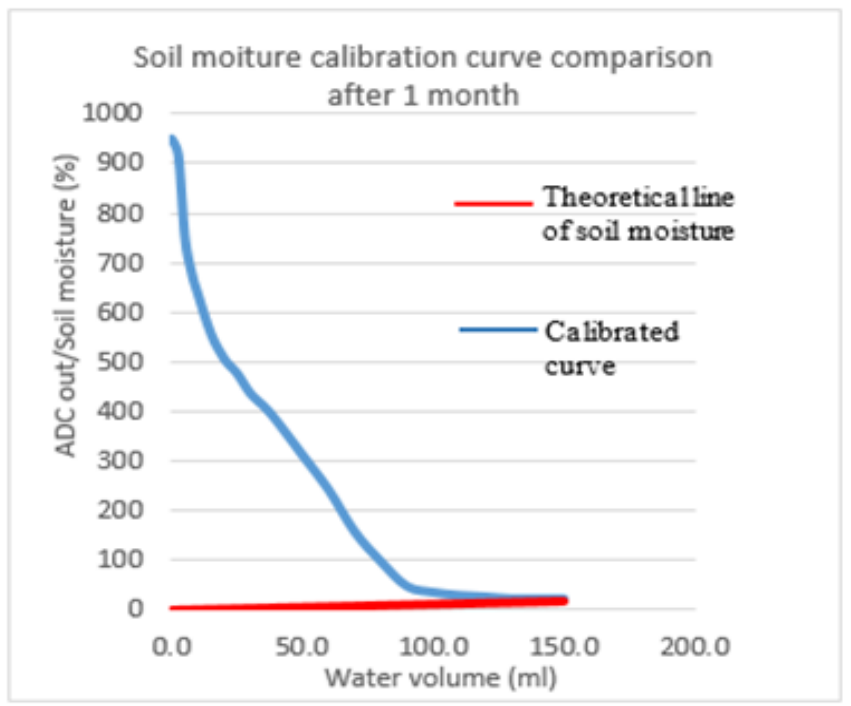

Figure 9: Calibration curve of the stainless steel soil moisture module

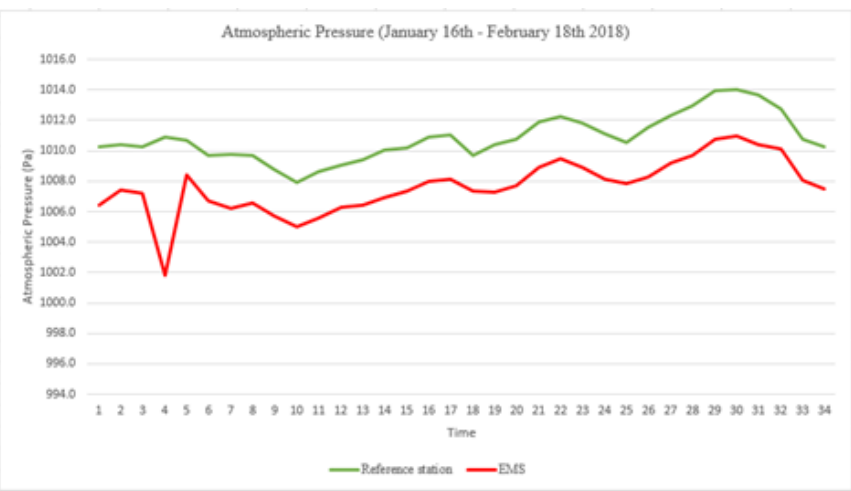

Figure 10: Atmospheric pressure records during the period of 16th January - 18th February 2018

The atmospheric pressure records were validated against the records of an official station belongs to Meteorological department. This station is located at a coastal belt, $4.5 \mathrm{~km}$ away from the prototype EMS station. Since the atmospheric pressure is usually higher at sea level, the reference station's records are slightly higher than the EMS records (Figure 10).

The data validation with reference to rainfall, wind direction, solar radiation and water level have not been shown in this study due to the unavailability of reliable reference data. However, this work will aim to validate the accuracy of all the sensor outputs by installing the EMS station and a reference station at a same location.

\section{Conclusion}

The delivered prototype demonstrates that open source based EMS system offers a platform for developing a cost effective, portable, easily installed and autonomous system which measures environmental parameters at a low cost. In doing so, it combines open hardware and open software technologies. The system is able to operate as a remote measurement system equipped with renewable energy source, wireless data communication, data logging and displaying facilities. At this stage the accuracy levels of the measurements have been validated following numerous procedures, under the constraints of unavailability of a nearby reference station which provides data on required nine environmental parameters. A number of works are being carried to analyze the system's durability and consistency in deploying them in the field. In addition, experiments are being carried to test the suitability of components in the main processing unit, power supply units and sensors against the fluctuating weather conditions and weather proofing the electrical and electronic units. While addressing all the pros and cons of the system, the authors wish to present the overall sustainability of the EMS system in terms of cost, durability, maintenance and quality of data in the near future.

\section{Acknowledgement}

Authors would like to thank Swiss Agency for Development and Cooperation (SDC) and Swiss National Science Foundation (SNSF) for providing necessary funds to carry out this research. 


\section{References}

Artiola, J.F., Pepper, I.L., Brusseau, M. (Eds.). (2004). Environmental Monitoring and Characterization. Burlington, MA: Elsevier Academic Press.

Bell, S., Cornford, D. and Bastin, L. (2013). The state of automated amateur weather observations. Weather, 68(2), pp.36-41.

Bitella, G., Rossi, R., Bochiccchio, R., Perniola, M., \& Amato, M. (2014). A novel low cost open hardware platform for monitoring soil water content and multiple soil-air-vegetation parameters. Sensors, 14, 19639 -19659.

Coetzee, L. and Eksteen, J. (2011). The Internet of Things-promise for the future? An introduction. In: IST-Africa Conference Proceedings. pp.1-9.

Evans, D. (2011). The Internet of Things: How the next evolution of the intenet is changing everything. Cisco Internet Business Solutions Group. Retrieved December 2016, from http://www.cisco.com/c/dam/en_us/about/ac79/ docs/innov/IoT_IBSG_0411FINAL.pdf

Formisano, F., Massera, E., \& De Vito, S. (2015). Tinynose, an Auxiliary smart gas sensor for RFID tag in vegetables ripening monitoring during refrigerated cargo transport. Retrieved May 2017, from https:// www.researchgate.net/publication/278668294

Goodchild, M. (2007). Citizens as sensors: the world of volunteered geography. GeoJournal, 69(4), pp.211-221.

GSMA, 2014. The Mobile Economy 2014 GSMA 2014. Available online at: http://www.gsmamobileeconomy.com/ GSMA_ME_Report_2014_R2_WEB.pdf [consulted on January 2015]

Huang, Y., \& Li, G. (2010). Huang, Y., \& Li, G. (2010). A Semantic Analysis for Internet of Things. IEEE - 2010 International Conference on Intelligent Computation Technology and Automation.

Mierzwa, S., Souidi, S., Austrian, K., Hewett, P., Isaac, A., Maimbolwa, M., \& Wu, C., 2014. Transitioning Customized ACASI Windows. NET Solution to Android Java on Lower-Priced Devices and Technical Lessons Learned. The Electronic Journal of Information Systems in Developing Countries, 66

Muller, C., Chapman, L., Johnston, S., Kidd, C., Illingworth, S., Foody, G., Overeem, A. and Leigh, R. (2015). Crowdsourcing for climate and atmospheric sciences: current status and future potential. International Journal of Climatology, 35(11), pp.3185-3203.

Prescott, E., Rome, C., Marchiori, A., \& Hayes, B. (2016). HydroSense: An open platform for hydroclimatic monitoring. Retrieved May 2017, from http://www.eg.bucknell.edu/wse/documents/journal_articles/ smartcomp2016.pdf

Presser, M., Eurich, M., Villalonga, C., \& Barnaghi, P. (2009). The SENSEI project: Integrating the physical with the digital world of the network of the future. IEEE Commun. Mag., 47, 1-4.

Ratnayake, R. (2017). Sense of safety in public spaces: University student safety experiences in an Australian regional city. Rural Society, 26(1), 69-84.

De Silva, C. S., Warusavitharana, E. J., \& Ratnayake, R. (2017). An examination of the temporal effects of environmental cues on pedestrians' feelings of safety. Computers, Environment and Urban Systems, 64, $266-274$.

Ratnayake, R. (2013). Environmental features and sense of safety. WIT Transactions on Ecology and the Environment, 179, 377-388.

Ratnayake, R. (2016). Fear of crime in urban settings: Influence of environmental features, presence of people and social variables. Bhumi, The Planning Research Journal, 3(2).

Ranasinghe, G., Amarawickrama, S., \& Rathnayake, R. (2016). A Study to Compare the Level of Walkability in Two Urban Neighborhoods of Sri Lanka. International Journal of Engineering Research and General Science, 4(1), 6 -13 .

Roggen, D., Troster, G., Lukowicz, P., Ferscha, A., Millan, J., \& Chavarriaga, R. (2013). Opportunistic human activity and context recognition. Computer, 46, 36-45.

Sadler, J., Ames, D., \& Khattar, R. (2014). Open hardware meets open software for environmental monitoring. 7th International congress of environmental modelling and software. Retrieved December 2016, from https:// www.researchgate.net/publication/264417370 
Samourkasidis, A., \& Athanasiadis, I. (2014). Towards a low cost, full service air quality data archival system. 7th International congress on environmental modelling and software. Retrieved December 2016, from http:// www.iemss.org/sites/iemss2014/papers/iemss2014_submission_300.pdf

Snow, J.T., 2013. Non-traditional Approaches to Weather Observations in Developing Countries. International Finance Corporation. Available online at: http:/www.ifc.org/wps/wcm/connect/ 91c3778042bd94eeb2c6be0dc33b630b/

NonTraditional+Approaches+to+Weather+Observations+in+Developing+Countries+-+John+Snow.pdf?

MOD=AJPERES [consulted on January 2015]

Ucklemann, D., Harrison, M., \& Michahelles, F. (2011). Architecting the Internet of Things. New York: Springer Heidelberg Dordrecht.

Wiersma, G.B. (Ed.) (2004). Environmental Monitoring. Boca Raton, FLA: CRC Press. 